\title{
Retrieval of Aerosol Optical Depth Using Satellite Data Associated with Ground-based Observations over Urban and Rural Areas
}

\author{
Le Thi LE1, Hang Thi Thuy HANG², Cuong Xuan $\mathrm{CAO}^{3}$, Nghia Viet NGUYEN ${ }^{3}$, \\ Long Quoc NGUYEN ${ }^{3}$, Ha Thi Thu LE³ , Lan Thi PHAM³ ${ }^{3}$, Chan Van LE³ ${ }^{3}$ Lin TANG-HUANG4 \\ 1 Thanh Hoa University of Culture, Sport and Tourism, Vietnam, lethiledhvhttd|@gmail.com \\ 2 Vietnam Institute of Geodesy and Cartography, Vietnam, thuyhangnguyen228@gmail.com \\ 3 Hanoi University of Mining and Geology, Vietnam, \\ caoxuancuong@humg.edu.vn, nguyenvietnghia@humg.edu.vn,nguyenquoclong@humg.edu.vn, \\ lethithuha@humg.edu.vn, phamthilan@humg.edu.vn, levancanh@humg.edu.vn \\ 4 National Central University, Taiwan, thlin@csrsr.ncu.edu.tw
}

\begin{abstract}
Aerosol optical depth (AOD) can be retrieved accurately with sequential ground-based measurements of direct and diffuse solar radiance. However, spatial coverage and location frequency cause certain limitations. Hence, satellite image data are a proper tool for obtaining aerosol optical depth products with more spatial information and patterns of aerosol distribution. Currently, aerosol remote sensing may enhance our understanding of the optimal approach to AOD retrieval over urban and rural areas, and how it differs due to the characteristics of surface reflectivity. The article deals with the concepts of contrast reduction, and dark target approaches are examined using Landsat imaging and the observation of a sun photometer for integrating aerosol optical depth distribution over the city of Taipei in Taiwan. For areas with bright surfaces, such as urban areas, the above concepts were applied using the dispersion coefficient method with a sun photometer, in order to reduce errors considerably in the product. In contrast, a dark target algorithm with a relationship of surface reflectance between the blue $(0.49 \mu \mathrm{m})$, red $(0.66 \mu \mathrm{m})$, and infrared $(2.1 \mu \mathrm{m})$ spectral bands is suitable for moist soils and vegetation areas. The retrieval of AOD spatial distribution is compared with MODIS AOD products and AERONET to verify the accuracy of the results. The RMSE ranged from 0.2 to 0.4 , and about $50 \%$ of the data were within expected error margins $\left(E E= \pm\left(0.05+0.15 A 0 D_{\text {sunphotometer }}\right)\right.$.
\end{abstract}

Keywords: aerosol optical depth, aerosol remote sensing, Taipei, Taiwan

\section{Introduction}

Aerosols are known to be associated with pollution in the local atmosphere (Fenger 1999). Small particle matter (PM) under 10 micrometers $(\mu \mathrm{m})$ poses a risk to human health when inhaled (Harrison et al. 2000). Inhalation of aerosol particles leads to a variety of complications, including irregular heartbeat, decreased lung function, non-fatal heart attacks, and aggravated asthma (Pope et al. 2002). Therefore, crucial importance is placed on aerosol research for PM concentrations to monitor the level of air pollution and take the necessary steps to prevent any further increase. Aerosols also play an integral role in a wide range of small and large scale weather and climate phenomena (Lenoble 2013). The need to establish aerosol optical depth distribution is therefore necessary for continuously monitoring changes over time and predicting influence on climate.

Air pollution occurs when gases or aerosol particles emitted anthropogenically and high agglomerate concentrations cause direct or indirect damage to humans, plants, animals, other life forms, ecosystems, structures, or works of art (Giese-Bogdan 1995). Taipei is a rapidly developing city where the high concentration of PM has a negative impact on the health of its residents. Owing to the extreme weather conditions in recent years, Taipei was selected as a study area in order to

KiG No. 32, Vol. 18, 2019, https://doi.org/10.32909/kg.18.32.1 - - 


\title{
Računanje optičke dubine aerosola na temelju satelitskih podataka povezanih s opažanjima na tlu u urbanim i ruralnim područjima
}

\author{
Le Thi LE1 1 , Hang Thi Thuy HANG², Cuong Xuan $\mathrm{CAO}^{3}$, Nghia Viet NGUYEN³, \\ Long Quoc NGUYEN 3 , Ha Thi Thu LE³ ${ }^{3}$ Lan Thi PHAM ${ }^{3}$, Chan Van LE³, Lin TANG-HUANG4 \\ 1 Thanh Hoa University of Culture, Sport and Tourism, Vietnam, lethiledhvhttd|@gmail.com \\ 2 Vietnam Institute of Geodesy and Cartography, Vietnam, thuyhangnguyen228@gmail.com \\ 3 Hanoi University of Mining and Geology, Vietnam \\ caoxuancuong@humg.edu.vn, nguyenvietnghia@humg.edu.vn,nguyenquoclong@humg.edu.vn \\ lethithuha@humg.edu.vn, phamthilan@humg.edu.vn, levancanh@humg.edu.vn \\ ${ }^{4}$ National Central University, Taiwan, thlin@csrsr.ncu.edu.tw

\footnotetext{
Članak je predan na engleskom jeziku. Na hrvatski ga je preveo V. Lapaine. The paper was submitted in English. It was translated into Croatian by V. Lapaine.
}

\begin{abstract}
Sažetak: Optičku je dubinu aerosola (AOD) moguće točno izračunati na temelju uzastopnih mjerenja izravnog i difuznog Sunčeva zračenja na tlu. Međutim, prostorna pokrivenost i frekvencija lokacije uzrokuju određena ograničenja. Stoga su satelitske snimke ispravan alat za dobivanje proizvoda optičke dubine aerosola s više prostornih informacija i obrazaca raspodjele aerosola. Daljinskim istraživanjima aerosola možemo bolje razumjeti najbolji pristup računanju optičke dubine aerosola u urbanim i ruralnim područjima i mogu se uočiti razlike zbog svojstava površinske reflektivnosti. Ovaj se članak bavi konceptima smanjenja kontrasta i pristupima tamnih meta koji se ispituju snimkama Landsata i opažanjima Sunčevog fotometra za povezivanje raspodjele optičke dubine aerosola iznad grada Taipeija u Tajvanu. Za područja sa svijetlim površinama kao što su gradovi navedeni se koncepti primjenjuju metodom koeficijenta disperzije zajedno sa Sunčevim fotometrom kako bi se u velikoj mjeri smanjile pogreške. Za razliku od toga, algoritam tamne mete s odnosom površinske refleksije između plavih $(0,49 \mu \mathrm{m})$, crvenih $(0,66 \mu \mathrm{m})$ i infracrvenih $(2,1$ $\mu \mathrm{m})$ spektralnih pojaseva prikladan je za vlažno tlo i područja s vegetacijom. Računanje prostorne raspodjele optičke dubine aerosola uspoređuje se s proizvodima MODIS AOD-a i AERONET-a kako bi se provjerila točnost rezultata. RMSE je bio u rasponu od 0,2 do 0,4 i oko $50 \%$ podataka bilo je unutar granica očekivane pogreške ( $E E= \pm\left(0,05+0,15 \mathrm{AOD}_{\text {sunphometer }}\right)$.
\end{abstract}

Ključne riječi: optička dubina aerosola, daljinsko istraživanje aerosola, Taipei, Tajvan

\section{Uvod}

Aerosoli su povezani sa zagađenjem lokalne atmosfere (Fenger 1999). Čestice koje su manje od 10 mikrometara $(\mu \mathrm{m})$, ako se nađu u plućima, opasnost su za ljudsko zdravlje (Harrison i dr. 2000). Udisanje čestica aerosola dovodi do različitih komplikacija uključujući nepravilne otkucaje srca, smanjenu funkciju pluća, nefatalne srčane udare i pogoršanje astme (Pope i dr. 2002). Stoga je ključno istraživati koncentraciju malih čestica $u$ aerosolu kako bi se nadgledala razina zagađenja zraka i poduzimale mjere sprečavanja daljnjeg zagađenja zraka. Aerosoli također igraju veliku ulogu u nizu vremenskih i klimatskih pojava malih i velikih razmjera (Lenoble 2013), stoga je određivanje raspodjele optičke dubine aerosola neophodno za neprekidno nadgledanje promjena kroz vrijeme i predviđanje njihovog utjecaja na klimu.

O zagađenju zraka govorimo kada velika koncentracija plinova ili čestica aerosola uzrokovanih ljudskim aktivnostima u dovoljnoj mjeri uzrokuje izravnu ili neizravnu štetu ljudima, biljkama i drugim oblicima života, ekosustavima, građevinama i umjetničkim djelima (Giese-Bogdan 1995). Taipei je grad koji se brzo razvija i u kojem visoka koncentracija malih čestica negativno utječe na zdravlje građana. Zbog ekstremnih vremenskih prilika posljednjih godina Taipei je odabran kao područje istraživanja za bolje razumije- 
understand better PM interaction. In the aerosol retrieval algorithm, the key factor estimated was the surface reflectance of the object. Two methods were employed: a) dispersion coefficient and b) dark target.

\section{Methodology}

The dark target and dispersion coefficient (contrast reduction) methods were applied to dark and bright surfaces in rural and urban areas. Groundbased measurements and MODIS-AOD products were used to validate AOD retrieval and identify the characteristics of types of aerosol. The general workflow followed to achieve the objective is shown in Figure 1.

\subsection{Dispersion Coefficient Method}

The dispersion coefficient method is based on contrast reduction, assuming ground reflectance is unchanged over time, and changes in aerosol properties are shown by variations in the apparent reflectance observed. If the environmental effect is considered identical in two adjacent pixels, the standard deviation of satellite observed radiance within a window area can be expressed as (Sifakis \& Deschamps 1992):

$$
\sigma\left(\rho^{*}\right)=\frac{T\left(\mu_{s}\right)\left[\sigma(\rho) \exp \left[\tau / \mu_{v}\right]\right]}{1-\langle\rho\rangle s} .
$$

If variations of surface reflectance are constant, which means it is constant, the proportion of standard derivation at the time can be obtained from the following equation (2):

$$
\Delta_{\tau}=\tau\left(t_{2}\right) / \mu_{v 2}-\tau\left(t_{1}\right) / \mu_{v 1}=\ln \left[\begin{array}{c}
\frac{\sigma\left(\frac{\rho^{*}}{t_{1}}\right)}{\overline{\rho_{t_{1}}^{*}}} \\
\frac{\sigma\left(\frac{\rho^{*}}{t_{2}}\right)}{\overline{\rho_{t_{2}}^{*}}}
\end{array}\right]
$$

where $\rho$ is reflectance; $\tau$ is the optical thickness of the atmosphere; $T\left(\mu_{s}\right)$ is the total transmission function on the Sun's ground path, and $\Delta$ is the difference between the pixels' ground reflectance. Equation (2) shows AOD at the time can be calculated if AOD at the reference time is known. This theory is supported by (Tanré et al. 1988). 


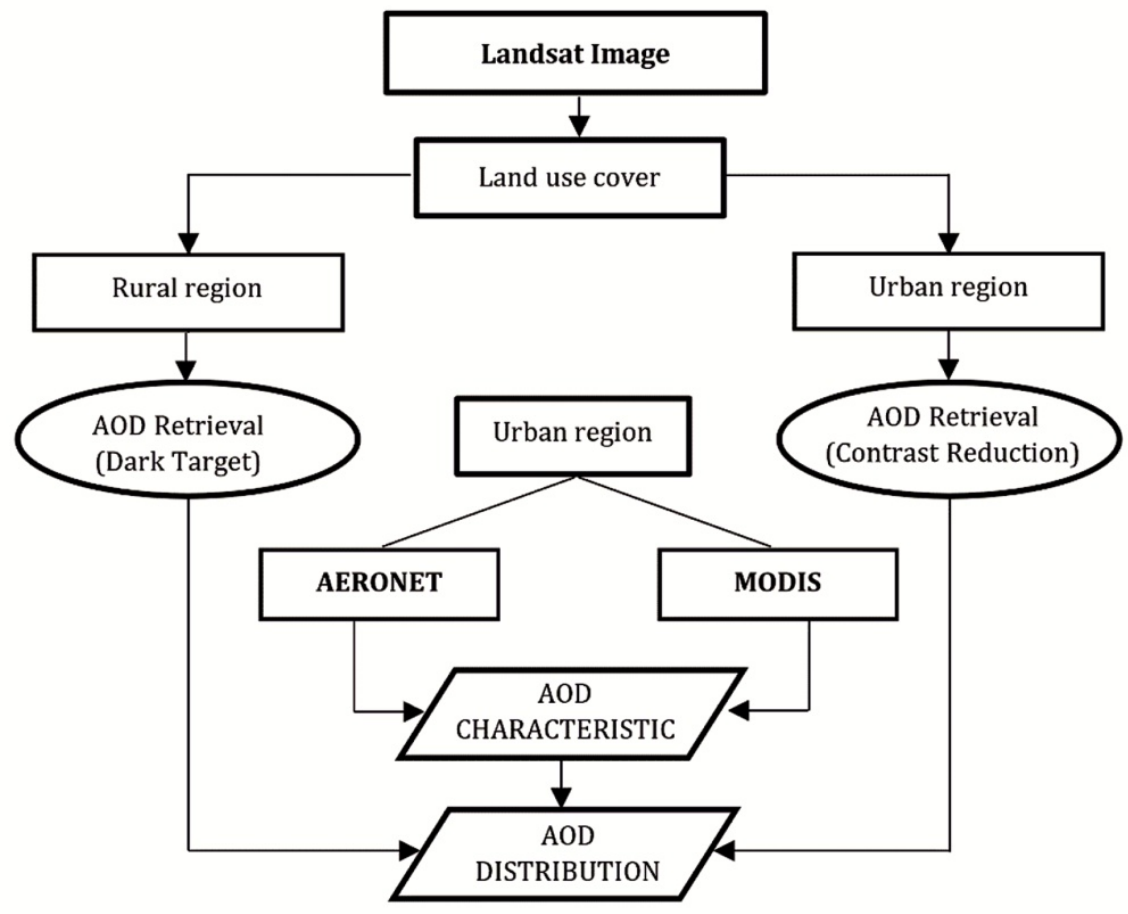

Slika 1. Prikaz tijeka rada.

Fig. 1 Overview of workflow methodology.

vanje utjecaja malih čestica. U algoritmu računanja aerosola ključni je čimbenik procjena površinske refleksije objekta. Upotrijebili smo dvije metode: a) koeficijent raspršenja, b) tamnu metu.

\section{Metodologija}

Metode tamne mete i koeficijenta raspršenja (smanjenje kontrasta) primijenjene su na tamnim i svijetlim površinama u urbanim i ruralnim područjima. Mjerenja na tlu i proizvodi MODIS-AOD-a upotrijebljeni su za određivanje valjanosti računanja optičke dubine aerosola. Također su utvrđena svojstva različitih tipova aerosola. Opći tijek rada prikazan je na slici 1.

\subsection{Metoda koeficijenta raspršenja}

Metoda koeficijenta raspršenja temelji se na smanjenju kontrasta (pod pretpostavkom da se refleksija tla ne mijenja), a promjene svojstava aerosola utvrđuju se na temelju promjena u vidljivoj refleksiji. Ako je utjecaj okoline jednak $u$ dvama susjednim pikselima, standardnu devijaciju sjaja unutar područja prozora moguće je izraziti kao (Sifakis i Deschamps 1992):

$$
\sigma\left(\rho^{*}\right)=\frac{T\left(\mu_{s}\right)\left[\sigma(\rho) \exp \left[\tau / \mu_{v}\right]\right]}{1-\langle\rho\rangle s} .
$$

Ako se zanemare razlike $u$ refleksiji površine ( $t j$. ako je ona konstantna) i proporcionalnost standardne devijacije s vremenom, može se dobiti jednadžba (2):

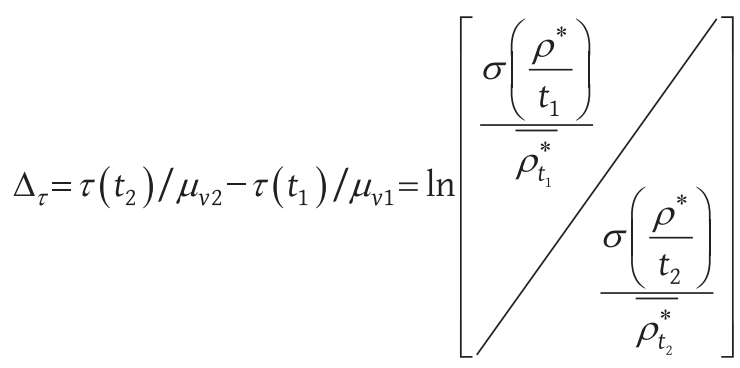

(2)

gdje je $\rho$ refleksija, $\tau$ optička debljina atmosfere, $T\left(\mu_{s}\right)$ funkcija ukupnog prijenosa na putu Sunca na tlu, a $\Delta$ razlika između refleksija tla među pikselima. Jednadžba (2) pokazuje da se AOD u nekom vremenu može izračunati i ovisi o poznavanju AOD-a u referentnom vremenu. Tu teoriju podržavaju također Tanré i dr. (1988).

\subsection{Metoda tamne mete}

S obzirom na to da aeorosoli u pravilu osvjetljavaju tamnu scenu, refleksija koju sateliti mjere veća je od sjaja koji se odbija od površine (Lenoble i dr. 2013). Metoda tamnog cilja temelji se na tehnici koju su predložili Kaufman i suradnici (1997), a koja se 


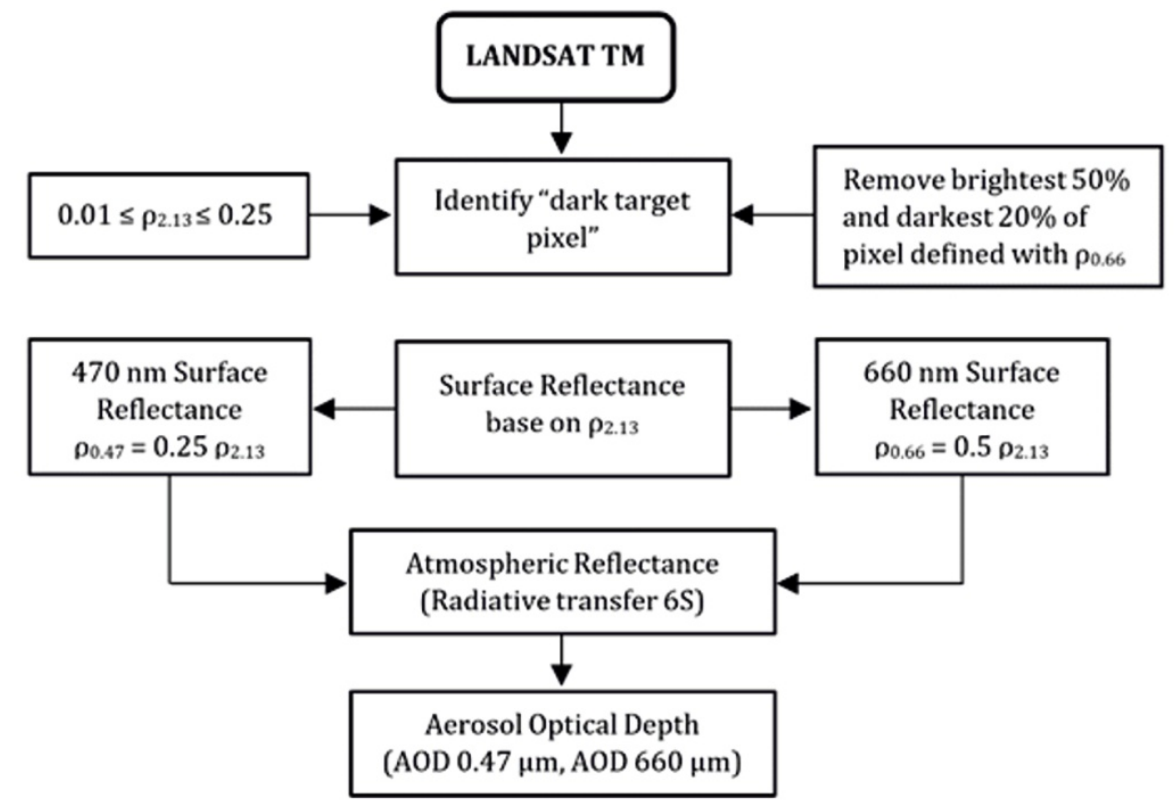

Fig. 2 Flow chart of the dark target algorithm.

Slika 2. Dijagram toka algoritma tamne mete.

error was used to measure the difference between them (Bilal et al. 2013). The larger $\mathrm{R}$ is, the better they agree, and the smaller the RMSE is, the higher the accuracy of the satellite AOD retrieval.

The RMSE was calculated as follow (4):

$$
R M S E=\sqrt{\frac{1}{n} \sum_{i=1}^{n}\left(A O D_{(\text {satellite })}-A O D_{\text {AERONET }}\right)^{2}}
$$

The mean absolute error (MAE) was estimated as:

$$
M A E=\frac{1}{n} \sum_{i=1}^{n}\left|A O D_{(\text {satellite })}-A O D_{\text {AERONET }}\right|
$$

where $A O D_{\text {(satellite) }}$ and $A O D_{(A E R O N E T)}$ were satellite AOD retrieval and AOD measured by the sun photometer (Bilal et al. 2013), respectively.

Standard deviation (STD) was calculated using the following formula:

$$
S T D=\sqrt{\frac{1}{n} \sum_{i=1}^{n}(x-\bar{x})^{2}}
$$

where $x$ and $\bar{x}$ were $A O D_{(\text {satellite) }}$ and the average $A O D_{(\text {satellite) }}$, respectively.

Expected error (EE) was used here for the confidence envelopes of the retrieval algorithm over land to evaluate the quality of satellite retrieval (Bilal et al. 2013):

$$
E E= \pm\left(0.05+0.15 A O D_{\text {sunphotometer }}\right)
$$

Good matches (quality) of satellite-retrieved AOD were reported when the satellite-retrieved AOD fell within the following envelope (Levy et al. 2010):

$$
A O D_{\text {sunphotometer }}-|E E| \leq A O D_{\text {satellite }} \leq A O D_{\text {sunphotometer }}+|E E| \text {. (8) }
$$

\section{Results and analyses}

4.1 AOD retrieval by the dispersion coefficient method

\subsubsection{Results of $A O D$ retrieval}

The dispersion coefficient method was conducted on the data for 29 May 2011, 25 August and 5 November 2011 for AOD retrieval over 8 locations (First Hotel Taipei, Banquiao Recreation Center, Luzhou, Sanchong, Taishan, Jieshou Park, Central Weather Bureau, and National Taiwan Museum). Six different window sizes were tested, including $5 \times 5,10 \times 10,16 \times 16,20 \times 20,32 \times 32$, and $40 \times 40$. The results for window size $5 \times 5$ are outlined in Figure 3 .

Table 1 illustrates the AOD observed from the AERONET station on the CWB site at wavelengths of 500,675 , and $870 \mathrm{~nm}$. These AOD were used in the next stage (Table 2). They comprise the mean, maximum, minimum, and standard deviations for each window size $(5 \times 5,10 \times 10,16 \times 16,20 \times 20,32 \times 32,40 \times 40)$. The accuracy of AOD retrieval was verified by two statistical parameters, including root mean square error and mean absolute error.

KiG No. 32, Vol. 18, 2019, https://doi.org/10.32909/kg.18.32.1 - ـ 


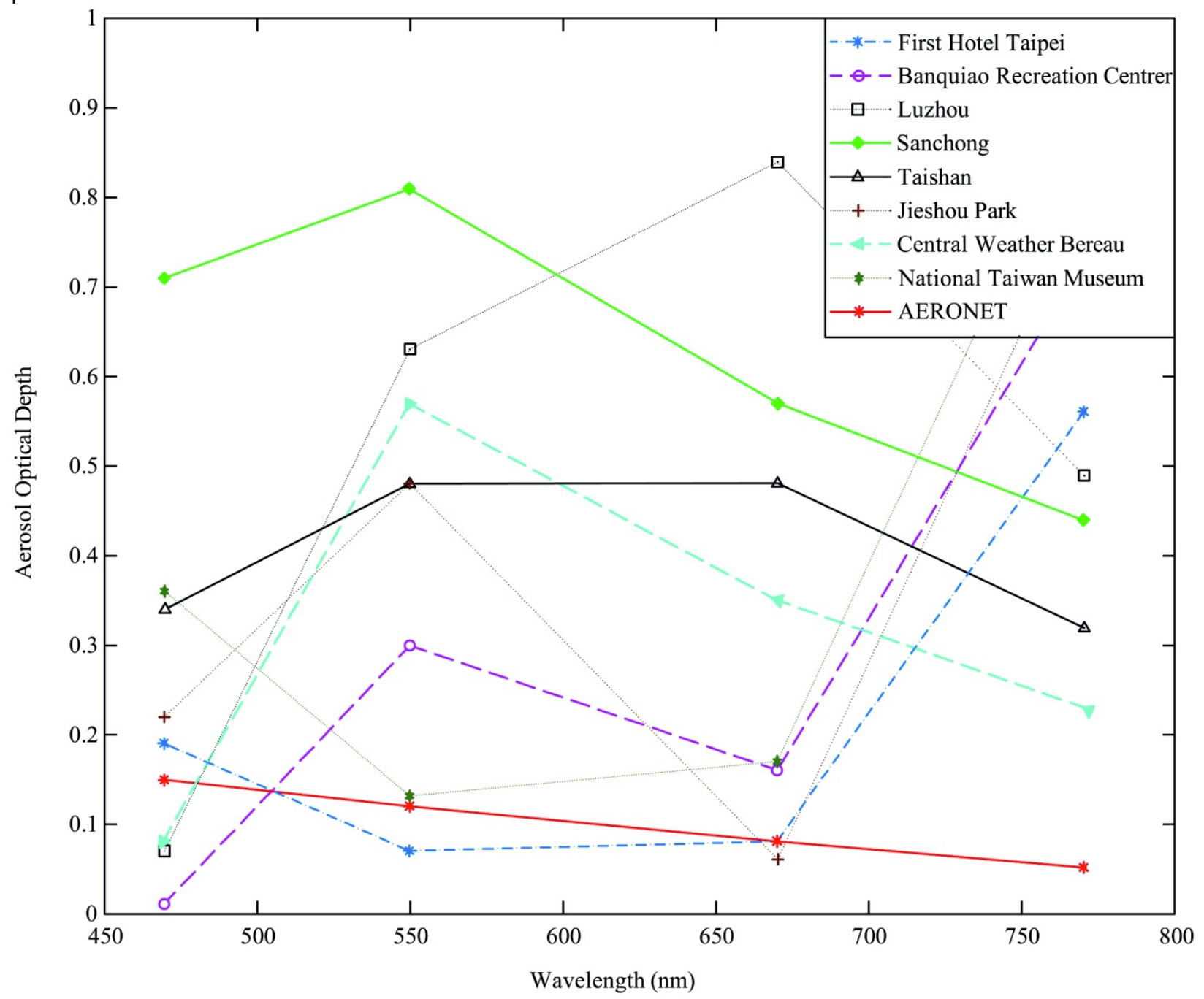

Slika 3. Optička dubina aerosola dobivena iz stanice na tlu u veličini prozora $5 \times 5$.

Fig. 3 AOD retrieval at the ground base station in $5 \times 5$ window size.

naziva tehnikom atmosferske korekcije. Tom je metodom moguće otkriti najtamnije piksele na slici. Ako pretpostavimo površinsku refleksiju tih piksela, možemo utvrditi količinu aerosola.

U ovom istraživanju, bez obzira na to je li cilj kopno ili ocean, kriteriji za metodu isključuju piksele vode, oblaka, leda i snijega. Nakon toga će tamna meta odabrati refleksiju 2,13 $\mu \mathrm{m}$ koja mora pasti u raspon 0,01 $\rho_{2,13} \leq 0,25$. Preostali se pikseli odnose na njihovu vidljivu refleksiju $\rho_{0,66^{\circ}}$. Dvadeset posto najtamnijih i $50 \%$ najsvjetlijih piksela miču se u refleksiju $\rho_{0,66}$. Razlog za to su sjene oblaka, neobična površina na tamnom kraju ili preostali oblak. Preostalih 30\% piksela odabrano je za računanje. Površinska refleksija na $0,47 \mu \mathrm{m}$ i 0,6 $\mu \mathrm{m}$ procijenjena je iz prosječne izmjerene vrijednosti pod pretpostavkom empirijskog odnosa plošne refleksije $u$ plavom $(0,49 \mu \mathrm{m})$, crvenom $(0,66 \mu \mathrm{m}) \mathrm{i}$ infracrvenom $(2,1 \mu \mathrm{m})$ te slijede proporciju (3) (Remer i dr. 2005):

$$
\rho_{0,49}=\left(\rho_{0,66}\right) / 2=\left(\rho_{2,1}\right) / 4
$$

gdje je $\rho$ refleksija.

Rayleighjeva korekcija i korekcija aerosola procijenjene su za svaku sliku upotrebom poznate nadmorske visine i prijenosnog koda zračenja 6s. Postoje dva trika za primjenu te metode: pronalaženje tamne guste vegetacije i pretpostavka refleksije površine na valnoj duljini pronalaska na slici. Dijagram toka prikazan je na slici 2.

\section{Procjena računanja aerosola}

Da bismo procijenili satelitske podatke o aerosolu, podatke dobivene Sunčevim fotometrom na tlu upotrijebili smo kao referentne podatke. Izračunali smo nekoliko statističkih pokazatelja kao što su: koeficijent korelacije, srednja apsolutna pogreška, korijen iz srednje kvadratne pogreške (root mean square error - RMSE), standardna devijacija i očekivana pogreška. Dok koeficijent korelacije pokazuje sličnost optičke dubine aerosola dobivenu uz pomoć satelita i one dobivene 
The dispersion coefficient method was tested on 29 May 2011 with different window sizes, and the results showed a fluctuation in the value of standard deviation. Standard deviation evidently decreases with an increase of window size (there was an expected minor exception in 10×10). There was no significant divergence between the results. Furthermore, the results of AOD retrieval errors did not show a linear relationship between window sizes.

Figure 4 and Figure 5 show the distribution of land cover types in the study area and the AOD distribution estimated from LANDSAT imagery acquired on 29 May 2011.
Table 1 AOD obtained from the AERONET station on the CWB site.

Tablica 1. Optička dubina aerosola dobivena na stanici AERONET u Central Weather Bureauu.

\begin{tabular}{llll} 
Date/ Datum & $870 \mathrm{~nm}$ & $675 \mathrm{~nm}$ & $500 \mathrm{~nm}$ \\
\hline 29/05/2011 & 0.157 & 0.214 & 0.325 \\
29.5.2011. & 0,157 & 0,214 & 0,325 \\
25/08/2011 & 0.064 & 0.017 & 0.128 \\
25.8.2011. & 0,064 & 0,017 & 0,128 \\
5/11/2011 & 0.108 & 0.136 & 0.198 \\
5.11.2011. & 0,108 & 0,136 & 0,198
\end{tabular}

Table 2 Descriptive statistics of AOD retrievals in each window size.

Tablica 2. Deskriptivna statistika optičkih dubina aerosola za svaku veličinu prozora.

$\begin{array}{lllllll}\text { Size/ Veličina } & 40 \times 40 & 32 \times 32 & 20 \times 20 & 16 \times 16 & 10 \times 10 & 5 \times 5 \\ \text { Median/ Medijan } & 0.695 / 0,695 & 0.765 / 0,765 & 0.96 / 0,96 & 1.28 / 1,28 & 0.91 / 0,91 & 0.67 / 0,67 \\ \text { Min/ Najmanja vrijednost } & 0.28 / 0,28 & 0.28 / 0,28 & 0.05 / 0,05 & 0.02 / 0,02 & 0.062 / 0,062 & 0.02 / 0,02 \\ \text { Max/ Najveća vrijednost } & 1.35 / 1,35 & 1.35 / 1,35 & 2.02 / 2,02 & 2.17 / 2,17 & 2.35 / 2,35 & 1.16 / 1,16 \\ \text { Mean/ Aritmetička sredina } & 0.69 / 0,69 & 0.77 / 0,77 & 0.92 / 0,92 & 1.04 / 1,04 & 1.12 / 1,12 & 0.90 / 0,90 \\ \text { STD/ Standardna devijacija } & 0.23 / 0,23 & 0.26 / 0,26 & 0.57 / 0,57 & 0.64 / 0,64 & 0.61 / 0,61 & 0.97 / 0,97\end{array}$

Table 3 Statistic of the AOD dispersion method and AERONET.

Tablica 3. Statistički podatci o optičkoj dubini aerosola dobiveni metodom koeficijenta raspršenja i AERONET-a.

\begin{tabular}{|c|c|c|c|c|c|}
\hline $\begin{array}{l}\text { Location/ } \\
\text { Lokacija }\end{array}$ & $\begin{array}{l}\text { RMSE/ } \\
\text { Korijen iz srednje } \\
\text { kvadratne pogreške }\end{array}$ & $\begin{array}{l}\text { MAE/ } \\
\text { Srednja apsolutna } \\
\text { pogreška }\end{array}$ & $\begin{array}{l}\text { MIN/ } \\
\text { Najmanja } \\
\text { vrijednost }\end{array}$ & $\begin{array}{l}\text { MAX/ } \\
\text { Najveća } \\
\text { vrijednost }\end{array}$ & $\begin{array}{l}\text { Data within EE/ } \\
\text { Podaci unutar granice } \\
\text { očekivane pogreške }\end{array}$ \\
\hline
\end{tabular}

First Hotel

Taipei

Banquiao City

Luzhou

Shanchong

Taishan

Jieshou Park

Central

Weather Bereau

National

Taiwan Museum
$0,35 / 0.35$

$0,41 / 0.41$

$0,44 / 0.44$

$0,37 / 0.37$

$0,28 / 0.28$

$0,357 / 0.357$

$0,42 / 0.42$

$0,43 / 0.43$
$0,27252 / 0.27252$

$0,36105 / 0.36105$

$0,38441 / 0.38441$

$0,39287 / 0.39287$

$0,32075 / 0.32075$

$0,31174 / 0.31174$

$0,39258 / 0.39258$

$0,35881 / 0.35881$
$0,07 / 0.07$

$0,96 / 0.96$

$50 \%$

\section{$0,01 / 0.01$}

$0,01 / 0.01$

$0,08 / 0.08$

$0,06 / 0.06$

$0,06 / 0.06$

$0,06 / 0.06$

$0,90 / 0.90$

$0,97 / 0.97$

$0,74 / 0.74$

$0,88 / 0.88$

$0,82 / 0.82$

$0,81 / 0.81$

$0,04 / 0.04$

$0,96 / 0.96$

\subsubsection{Comparison between AOD Satellite Retrieval and AERONET data}

Table 3 presents a comparison between AOD retrieval using the dispersion coefficient method and AERONET data at the CWB in Taipei. Statistical indicators such as root mean square error (RMSE), mean absolute error (MAE), minimum, maximum, and expected error (EE) were used for comparisons in eight locations.
These locations were Luzhou, Sanchong, First Hotel Taipei, Banquiao Recreation, Taishan, Jieshow Park, Central Weather Bureau, and the National Taiwan Museum. As presented in table 3, the AOD retrieval from the dispersion coefficient method achieved EE of nearly $50 \%$. Specifically, Taishan had the best result with $60 \%$ EE, followed by First Taipei Hotel and Sanchong with $50 \%$. At the other stations, the value of EE fluctuated between $40 \%$ and $45 \%$.

KiG No. 32, Vol. 18, 2019, https://doi.org/10.32909/kg.18.32.1 - 
Sunčevim fotometrima na tlu, korijen iz srednje kvadrirane pogreške pokazuje razliku među njima (Bilal i dr. 2013). Što je veći koeficijent korelacije, to je veća sličnost među optičkim dubinama aerosola, a što je manji korijen iz srednje kvadratne pogreške, veća je točnost optičke dubine aerosola dobivene uz pomoć satelita.

Korijen iz srednje kvadratne pogreške računa se na sljedeći način (4):

$$
R M S E=\sqrt{\frac{1}{n} \sum_{i=1}^{n}\left(A O D_{(\text {satellite })}-A O D_{\text {AERONET }}\right)^{2}}
$$

Srednja apsolutna pogreška (mean absolute error MAE) procjenjuje se kao:

$$
M A E=\frac{1}{n} \sum_{i=1}^{n}\left|A O D_{(\text {satellite })}-A O D_{\text {AERONET }}\right|
$$

gdje su $A O D_{\text {(satellite) }}$ i $A O D_{\text {(AERONET) }}$ optičke dubine aerosola dobivene satelitima i Sunčevim fotometrom (Bilal i dr. 2013).

Standardna devijacija (STD) računa se s pomoću sljedeće formule:

$$
S T D=\sqrt{\frac{1}{n} \sum_{i=1}^{n}(x-\bar{x})^{2}}
$$

gdje su $x$ i $\bar{x}$ oznake za $A O D_{(\text {satellite) }}$, odnosno sredina $\operatorname{od} A O D_{\text {(satellite) }}$.

Ovdje je upotrijebljena očekivana pogreška (expected error - EE) za intervale pouzdanosti algoritma računanja optičke dubine aerosola na tlu kako bi se procijenila kvaliteta podataka dobivenih pomoću satelita (Bilal i dr. 2013):

$$
E E= \pm\left(0,05+0,15 A O D_{\text {sunphotometer }}\right)
$$

O dobroj kvaliteti optičke dubine aerosola dobivene satelitima govorimo kada se ona nalazi $u$ intervalu (Levy i dr. 2010):

$$
A O D_{\text {sunphotometer }}-|E E| \leq A O D_{\text {satellite }} \leq A O D_{\text {sunphotometer }}+|E E| \text {. }
$$

\section{Rezultati i analize}

\subsection{Optička dubina aerosola dobivena metodom koeficijenta raspršenja}

\subsubsection{Rezultati računanja optičke dubine aerosola}

Metoda koeficijenta raspršenja primijenjena je na podatcima od 29. svibnja 2011., 25. kolovoza i 5. studenog
2011. na 8 lokacija (First Hotel Taipei, Banquiao Recreation Center, Luzhou, Sanchong, Taishan, Jieshou Park, Central Weather Bureau i National Taiwan Museum). Testirano je šest različitih veličina prozora, uključujući $5 \times 5,10 \times 10,16 \times 16,20 \times 20,32 \times 32$ i 40×40. Rezultati za veličinu prozora $5 \times 5$ prikazani su na slici 3 .

Tablica 1 prikazuje optičku dubinu aerosola opaženu sa stanice AERONET u Central Weather Bureauu na valnim duljinama od 500, 675 i $870 \mathrm{~nm}$. U sljedećoj fazi upotrijebili smo optičku dubinu aerosola (tablica 2). Sastoji se od artimetičke sredine, najmanje i najveće vrijednosti te standardne devijacije za svaku veličinu prozora $(5 \times 5,10 \times 10,16 \times 16,20 \times 20,32 \times 32,40 \times 40)$. Točnost dobivene optičke dubine aerosola provjerena je uz pomoć dvaju statističkih parametara, korijena iz srednje kvadratne pogreške i srednje apsolutne pogreške.

Metoda koeficijenta raspršenja primijenjena je 29. svibnja 2011. s različitim veličinama prozora, a rezultati upućuju na kolebanja vrijednosti standardne devijacije. Ona se očito smanjuje s povećanjem veličine prozora (uz očekivanu manju iznimku za veličinu 10×10). Također nema značajne razlike među rezultatima. Nadalje, odnos između veličine prozora i pogreške optičke dubine aerosola nije linearan.

Slike 4 i 5 prikazuju raspodjelu tipova pokrova tla $\mathrm{u}$ istraživanom području te raspodjelu optičkih dubina aerosola procijenjenih na temelju slika LANDSAT-a dobivenih 29. svibnja 2011.

\subsubsection{Usporedba optičkih dubina aerosola dobivenih sateli- tima s podatcima AERONET-a}

Tablica 3 prikazuje usporedbu optičkih dubina aerosola dobivenih metodom koeficijenta raspršenja i podataka AERONET-a iz Central Weather Bureaua u Taipeiu. Pokazatelji deskriptivne statistike kao što su korijen iz srednje kvadratne pogreške, srednja apsolutna pogreška, najmanja i najveća vrijednost te očekivana pogreška upotrijebljeni su za usporedbu na osam lokacija. Te su lokacije Luzhou, Sanchong, First Hotel Taipei, Banquiao Recreation, Taishan, Jieshow Park, Central Weather Bereau i National Taiwan Museum. Kao što je prikazano u tablici 3, optička dubina aerosola dobivena metodom koeficijenta raspršenja ima očekivanu pogrešku od gotovo $50 \%$. Točnije, Taishan ima najbolji rezultat sa $60 \% \mathrm{u}$ očekivanoj pogrešci, nakon čega slijede First Taipei Hotel i Sanchong s 50\%. Vrijednost očekivane pogreške na ostalim stanicama varira od $40 \%$ do $45 \%$.

Optička dubina aerosola dobivena metodom koeficijenta raspršenja ima veću razlučivost od proizvoda MODIS-AOD za urbana područja. Nesigurnost se može 


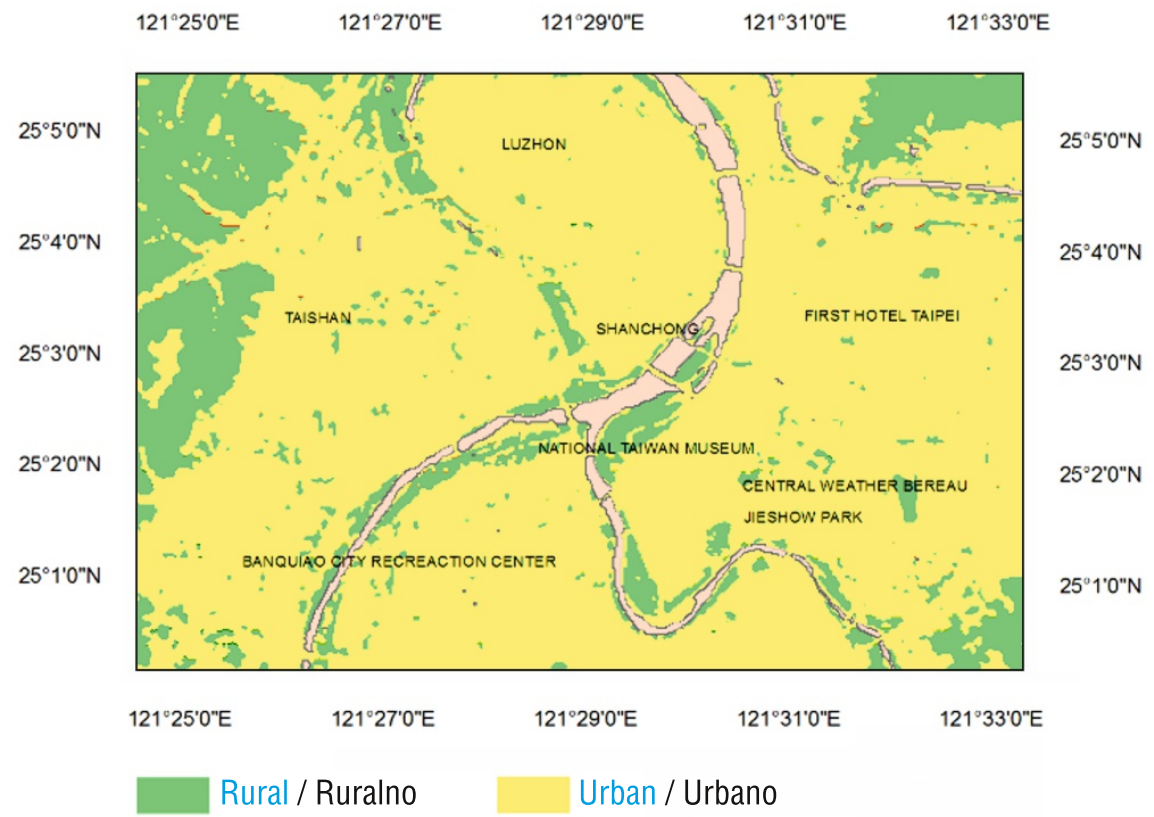

Fig. 4 Land cover classification map in the study area on 29 May 2011.

Slika 4. Karta klasifikacije pokrova tla u području istraživanja, 29. svibnja 2011.

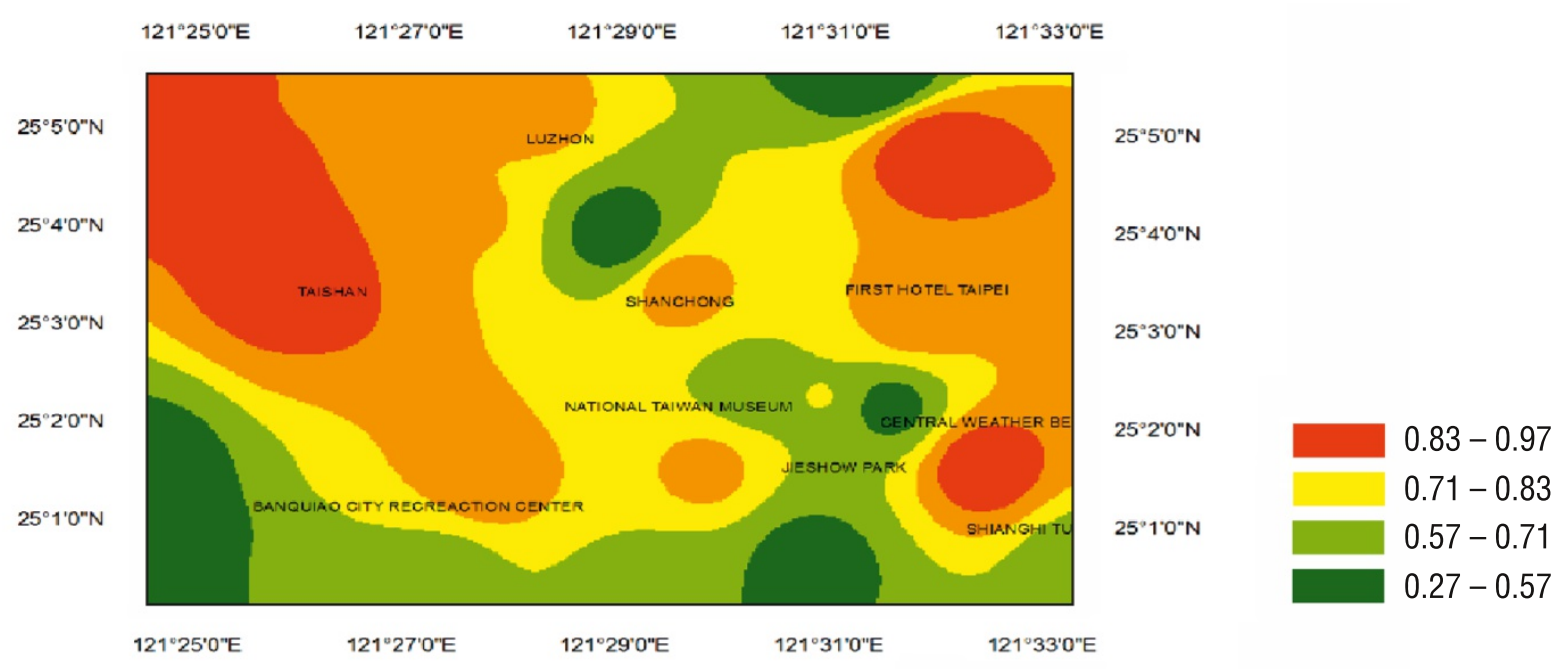

Fig. 5 AOD distribution over urban areas by the dispersion coefficient method.

Slika 5. Raspodjela optičke dubine aerosola iznad urbanih područja dobivena metodom koeficijenta raspršenja.

The AOD retrieved by the dispersion coefficient method had finer resolution in comparison with the MODIS-AOD product for urban areas. This anomaly may be because the surface reflectance was not invariable at each image location. In this method, we assumed that the surface reflectance did not change from day to day. Therefore, the method required multiple images of the same scene and near real time. Also, the scene had to display contrasts at a scale consistent with the sensor resolution.

\subsection{AOD retrieval by the dark target method}

\subsubsection{Results of $A O D$ retrieval by the dark target method}

The relationship between the reflectance in the blue band $(0.47 \mu \mathrm{m})$, red band $(0.66 \mu \mathrm{m})$ and infrared $(2.2 \mu \mathrm{m})$ channel were corrected on two images taken on 29 May and 5 November. Two locations in rural areas were chosen for aerosol retrieval: Fude Temple and Shangshi Tunnel. The

KiG No. 32, Vol. 18, 2019, https://doi.org/10.32909/kg.18.32.1 - - 


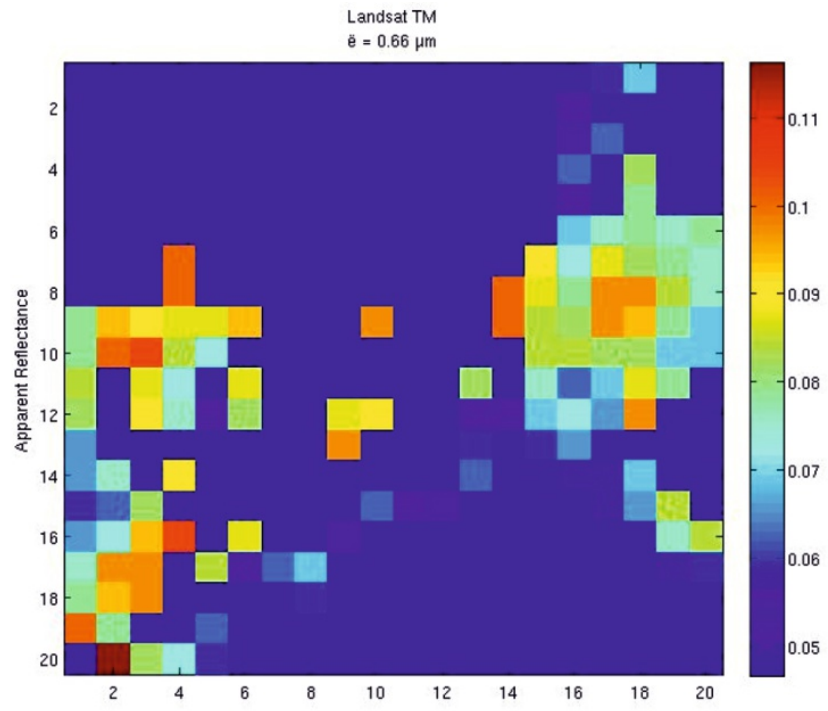

$6 a$

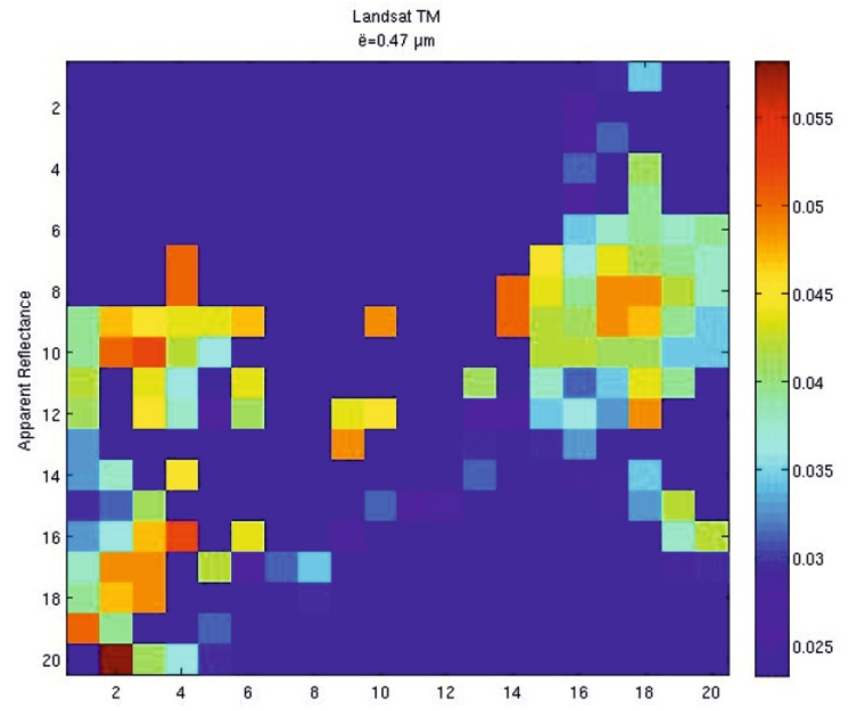

$6 \mathrm{~b}$

Slika 6. Vidljiva refleksija crvenog pojasa $(0,66 \mu \mathrm{m},(\mathrm{a}))$ i plavog pojasa $(0,47 \mu \mathrm{m}$, (b)) iz podataka prikupljenih 5. studenog 2011.

Fig. 6 Apparent reflectance of red band $(0.66 \mu \mathrm{m},(\mathrm{a}))$ and blue band $(0.47 \mu \mathrm{m},(\mathrm{b}))$ from images taken on 5 November 2011.

objasniti varijabilnošću refleksije plohe u svakom položaju slike. U toj smo metodi pretpostavili da se refleksija površine ne mijenja iz dana $u$ dan. Stoga ta metoda zahtijeva više slika iste scene $u$ gotovo realnom vremenu. Također, scena mora prikazivati kontraste na ljestvici dosljedno s razlučivošću senzora.

\subsection{Optička dubina aerosola dobivena metodom tamne mete}

\subsubsection{Rezultati računanja optičke dubine aerosola metodom tamne mete}

Odnos između refleksija $u$ plavom pojasu $(0,47$ $\mu \mathrm{m})$, crvenom $(0,66 \mu \mathrm{m})$ i infracrvenom $(2,2 \mu \mathrm{m})$ korigiran je u dvama slikama od 29. svibnja i 5. studenog. Kao lokacije u ruralnim područjima u kojima će se prikupiti podatci za određivanje optičke dubine aerosola izabrani su Fude Temple i Shangshi Tunnel. Vidljiva refleksija LANDSAT TM-a 0,47 $\mu \mathrm{m}$ i 0,66 $\mu \mathrm{m}$ te odgovarajuća optička dubina aerosola dobivena algoritmom tamne mete prikazani su na slikama 6a, $6 \mathrm{~b}, 7 \mathrm{a}$ i $7 \mathrm{~b}$.

\subsubsection{Usporedba prikupljanja podataka o optičkoj dubini aerosola i podataka AERONET-a}

Tablica 4 prikazuje usporedbu optičke dubine aerosola dobivene metodom tamne mete i AERONET-a 5. studenog 2011. Jasno se vidi da vrijednost očekivane pogreške varira između $4 \%$ i $26 \%$. Osim toga, korijen iz srednje kvadratne pogreške je između 0,04 i 0,74. Ti podatci pokazuju da taj algoritam ima veću točnost računanja optičke dubine aerosola. Atmosferska korekcija i podatci nebeskog radiometra upotrijebljeni su za računanje Rayleigheve korekcije, a analizarno je s pomoću načina $6 \mathrm{~S}$ za dobivanje AOD-a. To je dovelo do velikog smanjenja pogreške.

Ista je metoda primijenjena i na preostalih pet lokacija: Mochizuki, Yuan Tong Temple, Xindan, Zizhu Temple i Niubu Path. Metoda tamne mete vrlo je vrijedna jer omogućuje isključivanje raskoraka u rezultatima i olakšava usporedbu rezultata na svim lokacijama. U tablici 5 sažeti su podatci o optičkoj dubini aerosola dobivenoj metodom tamne mete u ruralnim područjima.

Dobro slaganje između optičke dubine aerosola dobivene metodom tamne mete i podataka AERONET-a za vrijeme opažanja na svakoj lokaciji potvrdili su snagu te metode. Srednji koeficijent korelacije, korijen iz srednje kvadratne pogreške i srednja apsolutna pogreška iznose 0,84, 0,06 i 0,05. Rezultati, dakle, pokazuju da je metoda tamne mete bolja za dobivanje optičke dubine aerosola u ruralnim područjima.

\subsubsection{Usporedba dobivene optičke dubine aerosola s podatcima MODIS-a}

Na području pokraj industrijskog grada uz sjevernozapadnu granicu dobiveno je veliko opterećenje 


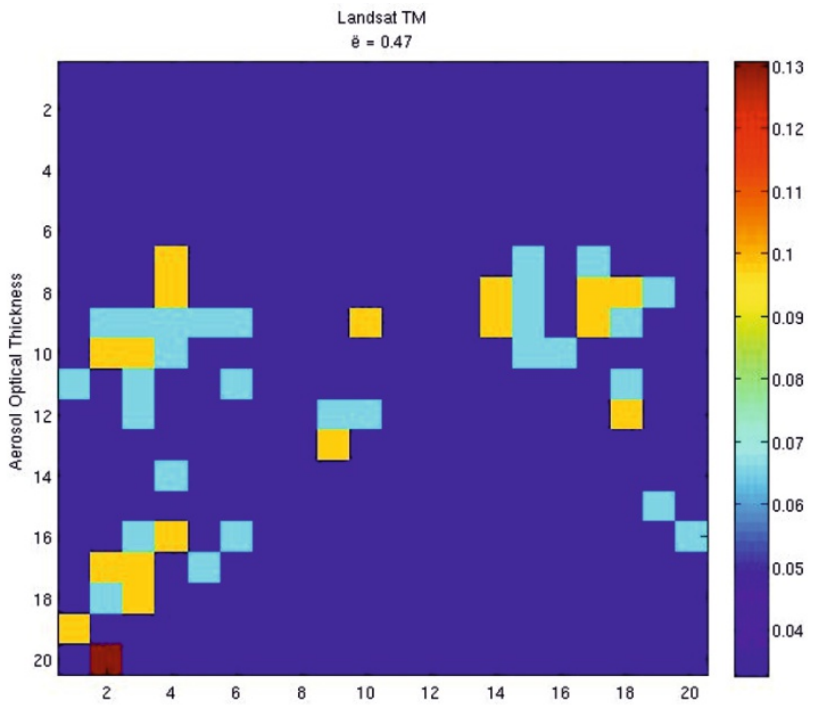

$7 \mathrm{a}$

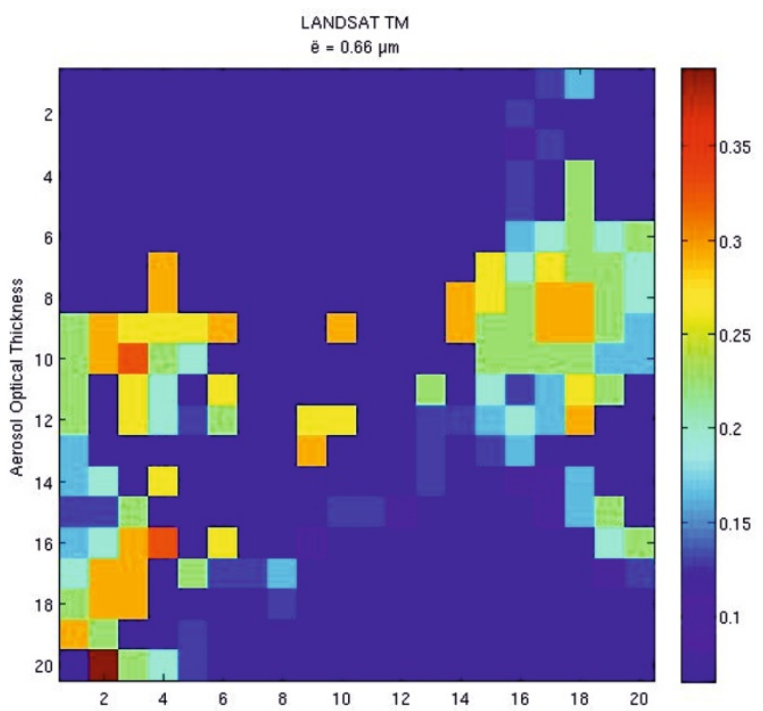

$7 \mathrm{~b}$

Fig. 7 AOD retrieval at Fude temple on 5 November 2011.

Slika 7. Prikupljanje podataka o optičkoj dubini aerosola u Fude Temple 5. studenog 2011.

Table 6 MODIS-AOD retrieval in this study.

Tablica 6. MODIS-AOD dobiveni u ovoj studiji.

\begin{tabular}{llccccc}
$\begin{array}{l}\text { Long/ } \\
\begin{array}{l}\text { Geografska } \\
\text { dužina }\end{array}\end{array}$ & $\begin{array}{l}\text { Lat/ } \\
\text { Geografska } \\
\text { širina }\end{array}$ & AOD 470 & AOD 660 & AOD 870 & AOD 1020 & AE \\
\hline & & & & & \\
$121,43 / 121.43$ & $24,954 / 24.954$ & $0,186 / 0.186$ & $0,104 / 0.104$ & $0,067853 / 0.067853$ & $0,053062 / 0.053062$ & $1,784 / 1.784$ \\
$121,30 / 121.30$ & $24,931 / 24.931$ & $0,264 / 0.264$ & $0,148 / 0.148$ & $0,096379 / 0.096379$ & $0,075287 / 0.075287$ & $1,784 / 1.784$
\end{tabular}

apparent reflectance of LANDSAT TM $0.47 \mu \mathrm{m}$ and $0.66 \mu \mathrm{m}$ and the corresponding AOD retrieved by the dark target algorithm are shown in Figures $6 \mathrm{a}$ and $6 b$, and Figures $7 a$ and $7 b$ respectively.

\subsubsection{Comparison Between AOD Retrieval and AERONET data}

Table 4 shows a comparison between the AOD retrieved by the dark target method and AERONET on 5 Nov 2011. It can be clearly seen that the EE value was between $4 \%$ and $26 \%$. In addition, the RMSE was from 0.04 to 0.74 . The accuracy of AOD retrieval using this algorithm was thus shown to be higher. Both atmospheric correction and sky radiometer data were used to calculate the Rayleigh correction. Analysis was carried out using the $6 \mathrm{~S}$ mode for retrieving AOD. It was highly associated with the reduction of error.

The other five locations, Mochizuki, Yuan Tong temple, Xindan, Zizhu temple, and Niubu Path were treated with the same method. The dark target method proved to be extremely valuable as it helped to exclude discrepancies in the results and made it easier to compare the results of all locations. The AOD retrieved by the dark target method in rural areas are summarized in Table 5.

A good level of agreement was found between the AOD retrieved by the dark target method and AERONET data during the observation period for each location, confirming the robustness of this method. The average correlation coefficient, RMSE, and MAE were 0.84, 0.06, and 0.05, respectively. Therefore, the results implied that the dark target method was better to retrieve the AOD accurately over rural areas.

\subsubsection{Comparison between AOD Retrieval and MODIS data}

In the northwest border area close to an industrial city, there was high aerosol loading (AOD 0.8). In Taipei, despite large spatial differences, the AOD was observed across urban and rural areas. The aerosol optical depth ranged from 0.2 to 0.8 . In this study, MODIS-AOD was obtained at the same AERONET locations. The AOD and Angstrom Exponent (AE) are tabulated in Table 6.

KiG No. 32, Vol. 18, 2019, https://doi.org/10.32909/kg.18.32.1 - - 
Tablica 4. Rezultati dobivanja AOD-a tamnim ciljem 5. studenoga 2011. Table 4 Results of AOD retrieval from dark target on 5 November 2011.

\begin{tabular}{|c|c|c|c|c|c|c|c|}
\hline $\begin{array}{ll}\lambda & \text { Lokacija/ } \\
\text { Location }\end{array}$ & $\begin{array}{l}\text { Aritmetička } \\
\text { sredina/ } \\
\text { MEAN }\end{array}$ & $\begin{array}{l}\text { Korijen iz } \\
\text { srednje } \\
\text { kvadratne } \\
\text { pogreške/ } \\
\text { RMSE }\end{array}$ & $\begin{array}{l}\text { Standardna } \\
\text { devijacija/ } \\
\text { SD }\end{array}$ & $\begin{array}{l}\text { Najmanja } \\
\text { vrijednost/ } \\
\text { Minimum }\end{array}$ & $\begin{array}{l}\text { Medijan/ } \\
\text { Median }\end{array}$ & $\begin{array}{l}\text { Najveća } \\
\text { vrijednost/ } \\
\text { Maximum }\end{array}$ & $\begin{array}{l}\text { Očekivana } \\
\text { pogreška (\%) } \\
\text { EE (\%) }\end{array}$ \\
\hline
\end{tabular}

$\begin{array}{lllllllll}0,47 / & \text { Fude } & 0,16 / 0.16 & 0,04 / 0.04 & 0,03 / 0.03 & 0,07 / 0.07 & 0,17 / 0.17 & 0,21 / 0.21 & 19 \\ 0.47 & \text { Temple } & & & & & & & \\ 0,47 / & \text { Shanghi } & 0,29 / 0.29 & 0,74 / 0.74 & 0,04 / 0.04 & 0,24 / 0.24 & 0,29 / 0.29 & 0,41 / 0.41 & 26 \\ 0.47 & \text { Tunnel } & & & & & & & \\ 0,66 / & \text { Fude } & 0,48 / 0.48 & 0,36 / 0.36 & 0,09 / 0.09 & 0,27 / 0.27 & 0,51 / 0.51 & 0,65 / 0.65 & 4 \\ 0.66 & \text { Temple } & & & & & & & \\ 0,66 / & \text { Shanghi } & 0,59 / 0.59 & 0,47 / 0.47 & 0,09 / 0.09 & 0,36 / 0.36 & 0,6 / 0.6 & 0,87 / 0.87 & 18 \\ 0.66 & \text { Tunnel } & & & & & & & \end{array}$

Tablica 5. Optička dubina aerosola dobivena metodom tamne mete u ruralnim područjima Taipeija.

Table 5 AOD retrieved by the dark target method in rural areas of Taipei.

\begin{tabular}{lll}
$\begin{array}{l}\text { Lokacija/ } \\
\text { Location }\end{array}$ & AOD (Retrieval) & AERONET \\
\hline Mochizuki & $0,228 / 0.228$ & $0,214 / 0.214$ \\
Yuan Tong temple & $0,261 / 0.261$ & $0,214 / 0.214$ \\
Xindan & $0,163 / 0.163$ & $0,214 / 0.214$ \\
Zizhu temple & $0,32 / 0.32$ & $0,214 / 0.214$ \\
Niubu Path & $0,163 / 0.163$ & $0,214 / 0.214$
\end{tabular}

Tablica 7. Usporedba MODIS-AOD-a i optičke dubine aerosola dobivene metodom tamne mete.

Table 7 Comparison between MODIS-AOD and the AOD retrieved by the dark target method.

\begin{tabular}{lll}
$\begin{array}{l}\text { Geografska } \\
\text { širina/ Lat }\end{array}$ & $\begin{array}{l}\text { Geografska } \\
\text { dužina/ Long }\end{array}$ & $\begin{array}{l}\text { Srednji AOD-MODIS/ } \\
\text { Mean AOD-MODIS }\end{array}$ \\
\hline 24,954/ 24.954 & $121,43 / 121.43$ & $0,24 / 0.24$
\end{tabular}

aerosolom (AOD 0,8). Unatoč velikim prostornim razlikama optička dubina aerosola u Taipeiju opažena je u urbanim i ruralnim područjima. Optička se dubina aerosola kreće $u$ rasponu od 0,2 do 0,8. $\mathrm{Na}$ istim lokacijama AERONET-a prikupili smo MODISAOD. Optička dubina aerosola i Angstromov eksponent prikazani su u tablici 6.
Kako bismo usporedili optičku dubinu aerosola dobivenu metodom tamne mete s MODIS-AOD-om, upotrijebili smo prostor veličine $20 \times 20$ piksela. Rezultat je prikazan u tablici 7.

Iako je postojala samo jedna stanica za usporedbu optičke dubine aerosola u području istraživanja, rezultati pokazuju veliko slaganje između optičke dubine aerosola dobivene MODIS-om i metodom tamne mete iz LANDSAT-a. Razlog tome su slični algoritmi. Na površini tla vrijednost površinske refleksije $u$ tamnim metama niska je $u$ dijelovima vidljivog i kratkovalnog infracrvenog spektra. Općenito govoreći, područja s vegetacijom i tamnim tlom primjeri su takvih tamnih meta. Osnovni algoritam upotrebljava dvije vidljive valne duljine, poput 0,47 i 0,65 $\mu \mathrm{m}$, te jedan kratkovalni infracrveni pojas $(2,1 \mu \mathrm{m})$ (Kaufman i dr. 1997, Levy i dr. 2007). Postoji, stoga, veliko slaganje između optičke dubine aerosola dobivene MODIS-om i metodom tamne mete iz LANDSAT-a.

Slika 8 prikazuje Banquiao Recreation Center, Taishan, i First Hotel Taipei, industrijska područja s velikom optičkom dubinom aerosola koja u tim područjima varira između 0,89 i 1. Druge stanice, poput National Taiwan Museum, Jieshow Park i Central Weather Bereau, imaju manje opterećenje aerosolom (između 0,6 i 0,8). Za razliku od toga, u ruralnim područjima kao što su Fude Temple, Zhizhu Temple i Niubu Path, optička dubina aerosola iznosi 0,16. Ta su područja daleko od industrijskih područja i manja se vrijednost optičke dubine aerosola može objasniti manjim zagađenjem zraka. 
In order to compare the AOD retrieved by the dark target method with the MODIS-AOD retrieval, we used a $20 \times 20$ pixel slicing window. The results are shown in Table 7.

Although there was only one station for comparing aerosol retrieval in the study area, the results showed a remarkable agreement between MODIS-AOD and dark target AOD from LANDSAT. This is because both had a similar algorithm. Over land surface, for the MODISAOD retrieval using the dark target algorithm, the value of surface reflectance in dark targets was low in parts of the visible and shortwave infrared spectrum. Generally, vegetation and dark soil areas are dark targets. The basic algorithm uses two visible wavelengths, such as 0.47 and $0.65 \mu \mathrm{m}$, and one shortwave infrared band $(2.1 \mu \mathrm{m})$ (Kaufman et al. 1997, Levy et al. 2007). Thus, the degree of agreement between MODIS AOD and dark target retrieved AOD from LANDSAT was considerable.

Figure 8 shows Banquiao Recreation Center, Taishan, and First Hotel Taipeim which are in industrial regions and have high aerosol optical thickness. There was a fluctuation of between 0.89 and 1 in the AOD value in these locations. Other stations, such as the National Taiwan Museum, Jieshow Park, and Central Weather Bureau, had a decrease in aerosol loading from 0.6 to 0.8 . In contrast, the AOD was 0.16 in rural areas such as Fude Temple, Zhizhu Temple, and Niubu Path. This may be because these observation points are located far from industrialized areas; the lower the value of satellite AOD retrieval depicted, the less the air pollution.

\section{Conclusions}

AOD retrieved by the dispersion coefficient method was associated with AERONET data. Contrast reduction methods successfully demonstrated improvement in obtaining a higher accuracy of atmospheric aerosol optical depth retrieval. The RMSE was from 0.2 to 0.4 , and about $50 \%$ of data were within the expected margin of error $(E E= \pm(0.05+0.15$ $\mathrm{AOD}_{\text {sunphotometer }}$ ). The anomalies of this method may be explained by simplification in variant surface reflectance, interaction between the surface and atmosphere, or atmospheric radiation assumption when estimating the AOD. In addition, the dispersion coefficient result showed a significant difference due to the difference in window sizes. AOD retrieval errors did not show a linear relationship with window sizes. Urban areas had a finer resolution of AOD in the application of the dispersion coefficient method to Landsat data.
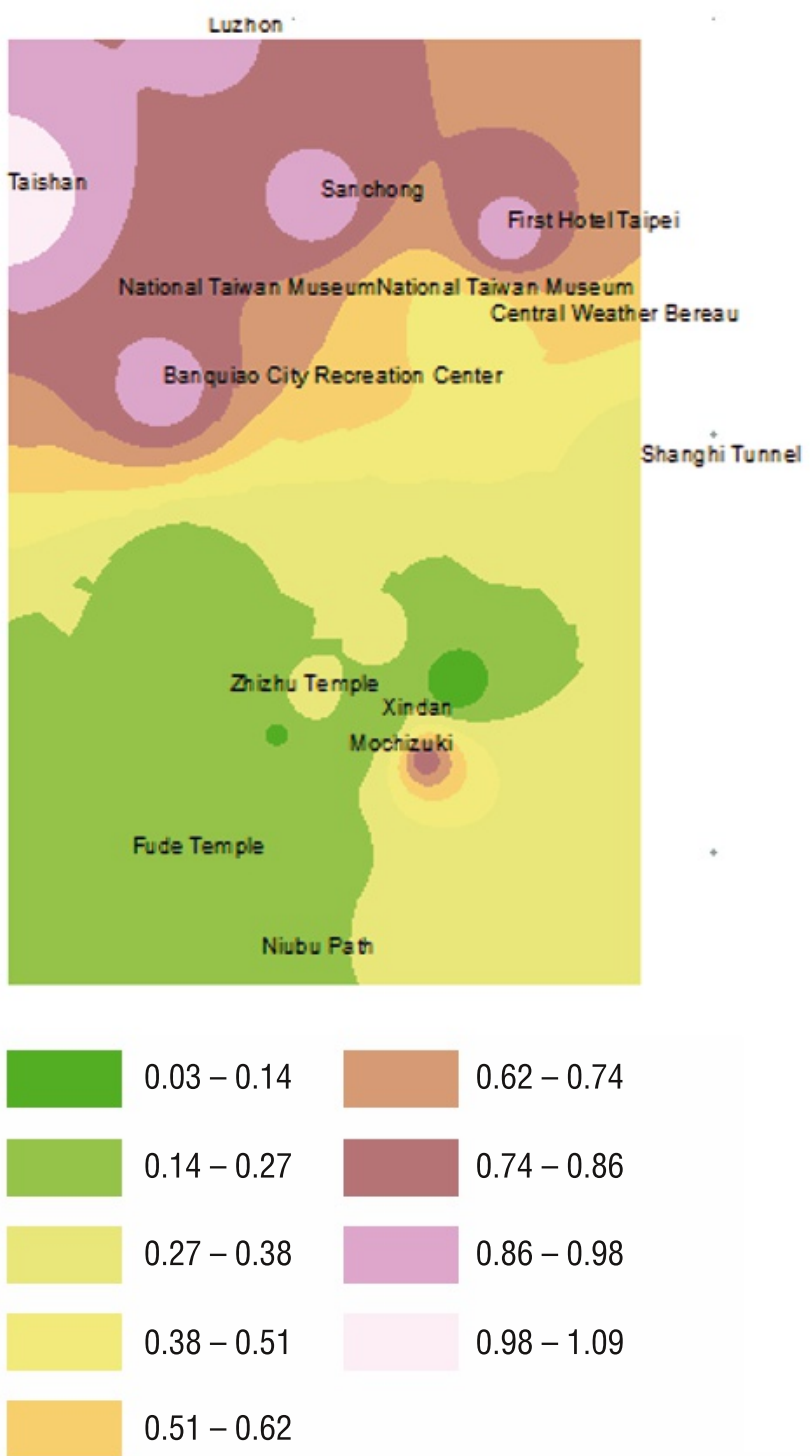

Fig. 8 Spatial distribution of AOD over study areas on 29 May 2011.

Slika 8. Prostorna raspodjela optičke dubine aerosola za područje istraživanja 29. svibnja 2011.

The dark target retrieval AOD was closely related to AERONET and MODIS-AOD. The result of comparison with AERONET measurements revealed a high correlation between remotely sensed values and ground base measurements, with a correlation coefficient of 0.84 . The uncertainty in the derivation was due to errors of $4-26 \%$ regarding aerosol optical thickness. The selection of dark pixels ensured 'strong pixels', which improved the accuracy of this method along with the atmospheric correction process.

\section{Acknowledgements}

This paper was supported by the Research Center for Mining Electro-Mechanics of Hanoi University of Mining and Geology (HUMG).

KiG No. 32, Vol. 18, 2019, https://doi.org/10.32909/kg.18.32.1 - - 


\section{Zaključci}

Optička dubina aerosola dobivena metodom koeficijenta raspršenja povezana je s podatcima AERONET-a. Metodama smanjenja kontrasta vjerojatno je povećana točnost atmosferske optičke dubine aerosola. Korijen iz srednje kvadratne pogreške kreće se od 0,2 do 0,4 i oko 50\% podataka nalazi se unutar granica očekivanja (EE $= \pm$ $\left(0,05+0,15 \mathrm{AOD}_{\text {sunphotometer }}\right)$. Nesigurnost metode može se pojednostavljeno objasniti razlikama $\mathrm{u}$ refleksiji površine, međudjelovanjem površine i atmosfere ili pretpostavkom o atmosferskoj radijaciji pri procjeni optičke dubine aerosola. Osim toga, rezultat koeficijenta raspršenja pokazuje značajnu razliku zbog razlika u veličinama prozora. Pogreške optičke dubine aerosola nisu bile linearno povezane s veličinom prozora. Urbana područja imaju finiju rezoluciju AOD-a kad se primijeni metoda koeficijenta raspršenja na podatke Landsata.

Metoda tamne mete blisko je povezana s AERONET-om, kao i s MODIS-AOD-om. Usporedba s mjerenjem AERONET-a pokazala je visoku korelaciju između podataka dobivenih daljinskim istraživanjima i onih dobivenim mjerenjima na terenu, pri čemu koeficijent korelacije iznosi 0,84, dok je nesigurnost u izvođenju s pogreškama od $4 \%$ do $26 \%$ optičke dubine aerosola. Odabir tamnih piksela osigurava „snažne piksele“, kao i postupak atmosferske korekcije, što poboljšava točnost te metode.

\section{Zahvala}

Ovaj je rad podržao Istraživački centar za rudarsku elektromehaniku Sveučilišta rudarstva i geologije u Hanoiju (Hanoi University of Mining and Geology - HUMG).

\section{References / Literatura}

Bilal M, Nichol J E, Bleiweiss M P, Dubois D (2013) A Simplified high-resolution MODIS Aerosol Retrieval Algorithm (SARA) for use over mixed surfaces. Remote sensing of environment 136, 135-145

Fenger J (1999) Urban air quality. Atmospheric environment 33(29), 4877-4900

Giese-Bogdan S (1995) From Michigan to Taiwan: Air Pollution Technology: Ann Arbor, MI: MPublishing, University of Michigan Library

Harrison R M, Yin J (2000) Particulate matter in the atmosphere: which particle properties are important for its effects on health. Science of The Total Environment 249(1), 85-101, doi: http://dx,doi,org/10,1016/S0048-9697(99) 00513-6

Kaufman Y J, Tanré D, Remer L A, Vermote E, Chu A, Holben B (1997) Operational remote sensing of tropospheric aerosol over land from EOS moderate resolution imaging spectroradiometer. Journal of Geophysical Research: Atmospheres 102(D14), 17051-17067

Lenoble J (2013) Aerosol Remote Sensing, Berlin, Heidelberg: Springer

Lenoble J, Mishchenko M I, Herman M (2013) Absorption and scattering by molecules and particles. Aerosol Remote Sensing, 13-51, Springer

Levy R C, Remer L A, Mattoo S, Vermote E F, Kaufman Y J (2007) Second-generation operational algorithm: Retrieval of aerosol properties over land from inversion of Moderate Resolution Imaging Spectroradiometer spectral reflectance. Journal of Geophysical Research: Atmospheres, 112(D13)

Levy R, Remer L, Kleidman R, Mattoo S, Ichoku C, Kahn R, Eck T (2010) Global evaluation of the Collection 5 MODIS dark-target aerosol products over land. Atmospheric Chemistry and Physics 10(21), 10399-10420

Pope III CA, Burnett RT, Thun MJ, Calle EE, Krewski D, Ito K, Thurston GD (2002) Lung Cancer, Cardiopulmonary Mortality, and Long-term Exposure to Fine Particulate Air Pollution. JAMA. 287(9):1132-1141. doi:10.1001/jama.287.9.1132

Remer L A, Kaufman Y J, Tanré D, Mattoo S, Chu D A, Martins J V, Li, R-R, Ichoku C, Levy R C, Kleidman R G, Eck T F, Vermote E, Holben B N (2005) The MODIS aerosol algorithm, products, and validation. Journal of the atmospheric sciences 62(4), 947-973

Sifakis N, Deschamps P Y (1992) Mapping of air pollution using SPOT satellite data. Photogrammetric Engineering and Remote Sensing LVIII, 1433-1437

Tanré D, Deschamps P, Devaux C, Herman M (1988) Estimation of Saharan aerosol optical thickness from blurring effects in Thematic Mapper dana. Journal of Geophysical Research: Atmospheres 93(D12), 15955-15964 